\title{
A PRESENÇA DA LIBRAS NO ENSINO DE MATEMÁTICA PARA ESTUDANTES SURDOS
}

\author{
Denner Dias Barros
}

Universidade Estadual Paulista Júlio de Mesquita Filho - UNESP, Pós-Graduação em Educação Matemática, Rio Claro, SP. E-mail: dennerdias12@gmail.com. Agência de fomento: CAPES

\section{RESUMO}

O objetivo deste estudo foi refletir sobre a presença da língua de sinais na educação de surdos e discutir sobre os reflexos das particularidades linguísticas destes estudantes nas aulas de Matemática a partir de pesquisas em Educação Matemática. Este processo de investigação teve o intuito de fundamentar teoricamente o estudo de mestrado intitulado "Libras e a formação de professores de Matemática na perspectiva da Educação Inclusiva". Em uma perspectiva qualitativa, esta investigação se enquadra como um estudo de caso e busca investigar uma disciplina de Libras para um curso de licenciatura em Matemática. Este recorte da pesquisa propiciou uma compreensão sobre a importância da Libras no ensino de Matemática para surdos, o que favoreceu o olhar acerca da organização da disciplina.

PALAVRAS-CHAVE: Educação Matemática, Surdez, Libras, Educação de surdos, Educação Inclusiva.

\section{THE PRESENCE OF LIBRAS IN MATHEMATICS TEACHING FOR DEAF STUDENTS}

\begin{abstract}
The objective of this study was to reflect on the presence of sign language in the education of deaf people and to discuss the reflexes of the linguistic peculiarities of these students in Mathematics classes from studies in Mathematics Education. This research process had the purpose of theoretically substantiating the master's study entitled "Libras and the formation of teachers of Mathematics in the perspective of Inclusive Education". In a qualitative perspective, the research that fits as a case study, seeks to investigate a discipline of Libras for a degree course in Mathematics. This cut of the research provided an understanding about the importance of Libras in the teaching of Mathematics for the deaf, which favored the look about the organization of the discipline.
\end{abstract}

KEYWORDS: Mathematics Education, Deafness, Libras, Education for the Deaf, Inclusive Education. 


\section{INTRODUÇÃO}

Com a democratização do acesso à educação, a escola tem se tornado cada vez mais um espaço para todos. Com a instituição de preceitos que valorizam não apenas o acesso, mas a permanência de todos nas escolas, os sistemas de ensino necessitam cada vez mais de mudanças que favoreçam com que as escolas tenham condições de que todos aprendam. Um dos marcos desse processo é a Declaração de Salamanca (1994), que preconiza o direito à educação para todos, considerando as habilidades e necessidades dos estudantes como únicas. Além disso, as escolas regulares são reconhecidas como os ambientes mais eficazes para o combate de discriminações e para propiciar uma sociedade mais inclusiva.

No Brasil, a escolarização dos Estudantes Público-Alvo da Educação Especial ${ }^{1}$ (EPAEE) é garantida através das Diretrizes Nacionais para a Educação Especial na Educação Básica (Resolução do Conselho Nacional de Educação/Câmara de Educação Básica no 2/2001). Essas diretrizes, assim como a Declaração de Salamanca (1994), reforçam os ideais de educação para todos e afirmam que cabe às instituições de ensino a organização para atender os EPAEE e garantir igualdade de oportunidades para todos. A inclusão pode ser descrita como:

Um movimento ligado à valorização de TODAS as pessoas, independentes de suas diferenças individuais, inclusive àquelas com deficiências. A sociedade transforma as estruturas vigentes (valores, acessibilidade, legislação, formação profissional etc.) para garantir a plena participação de todos. Educação de qualidade para TODOS em um processo bilateral, com o qual as pessoas ainda excluídas e a sociedade possam contar a fim de equacionar problemas, encontrar soluções e efetivar a equiparação de oportunidades (FERNANDES, 2007, p. 45-46).

Atualmente, a Política Nacional de Educação Especial na Perspectiva da Educação Inclusiva (2008) norteia o trabalho dos profissionais da educação para o ensino segundo os ideais da inclusão. Este documento traz diretrizes sobre o Atendimento Educacional Especializado (AEE), que engloba recursos e serviços ofertados aos EPAEE no contraturno em que o estudante frequenta a sala comum do ensino regular de ensino com os demais estudantes. Assim, a presença de professores especialistas em Educação Especial se torna importante no ambiente escolar, para trabalhar no AEE, com caráter complementar ou suplementar, e auxiliar no trabalho dos professores da sala comum, com estes estudantes.

Dentre os EPAEE, a educação dos estudantes surdos merece destaque por possuírem particulares linguísticas provenientes da modalidade de comunicação que utilizam. "O surdo, mesmo que ele e sua família não saibam de sua surdez, irá usar um canal para ter acesso às informações do mundo: o canal visual" (Moura, 2014, p.15). Entretanto, devemos reconhecer que estes sinais desenvolvidos não configuram uma comunicação através de uma língua de sinais.

A criança surda cria sinais caseiros que utiliza com sua família como uma forma de comunicar-se dentro do contexto familiar. Entretanto, as línguas de sinais são convencionadas pela comunidade surda e possuem diversas particularidades que devem ser consideradas ao trabalhar com este público.

A Lei 10.436/2002 reconhece a legitimidade da Língua Brasileira de Sinais (Libras). De acordo com a legislação, ela pode ser entendida como um meio de comunicação oficial das comunidades surdas do Brasil. Por intermédio deste reconhecimento, os surdos buscaram outros direitos fundamentais, como a garantia de uma educação em uma perspectiva bilíngue, garantida pelo decreto 5626/2005, onde a educação para estes estudantes será ofertada tendo como primeira língua a Libras e a língua portuguesa na modalidade escrita como segunda língua.

\footnotetext{
${ }^{1}$ Pessoas com deficiências físicas, sensoriais e múltiplas; Transtornos do Espectro Autista (TEA) e Altas Habilidades/Superdotação. 
Este decreto estabelece diversas diretrizes, principalmente na área educacional, que norteiam desde o atendimento aos estudantes surdos na escola até a formação dos profissionais que irão trabalhar com estes estudantes nas instituições de ensino. No capítulo II, artigo 3으, a Libras é inserida como disciplina obrigatória nos cursos de formação de professores e fonoaudiologia, tendo as instituições públicas e privadas, o prazo de 10 anos para se adequarem e inserirem a Libras nos currículos de seus cursos.

Este artigo está vinculado a pesquisa de mestrado em andamento, intitulada "Libras e a formação de professores de Matemática na perspectiva da Educação Inclusiva", que tem como objetivo compreender, a partir de um estudo de caso, que aspectos de uma disciplina de Libras podem contribuir para a formação de egressos de um curso de licenciatura em matemática, no que diz respeito a Educação Matemática na perspectiva da inclusão.

O objetivo deste artigo, que é um recorte da pesquisa de mestrado, foi refletir sobre a presença da língua de sinais na educação de surdos e discutir sobre os reflexos das particularidades linguísticas destes estudantes nas aulas de Matemática a partir de estudos em Educação Matemática para fundamentar teoricamente o estudo de mestrado.

\section{METODOLOGIA}

A metodologia adotada para a pesquisa enquadra-se em uma perspectiva qualitativa. Este tipo de estudo, para Goldenberg (2004), favorece um olhar para as singularidades de fenômenos, cuja identificação não pode ser proveniente de questionários padronizados e possibilita ao pesquisador fazer uso das mais diversas técnicas de produção e análise dos dados.

Neste recorte da pesquisa, retratamos uma das etapas iniciais, que foi composta de um levantamento bibliográfico para compreender melhor o papel da disciplina de Libras na formação dos professores da sala regular e, mais especificamente do professor de Matemática, buscamos estudos que discutem acerca do ensino de Matemática para surdos.

Para ter um panorama geral sobre as produções científicas já realizadas no Brasil que investigavam sobre a presença de estudantes surdos nas aulas de Matemática, realizamos uma busca sobre artigos, dissertações e teses sobre esta temática no portal de periódicos e no banco de teses e dissertações da CAPES, Google Acadêmico e Scielo.

Para a busca, foram utilizadas combinações entre as palavras-chave: Língua Brasileira de Sinais, Libras, Matemática, Educação Matemática, Ensino de Matemática, Surdez. Foram selecionados os trabalhos que apresentavam discussões sobre a presença da Libras no ensino de Matemática para surdos e que serão apresentados a seguir.

\section{RESULTADOS}

Diversas pesquisas têm sido desenvolvidas na área da Educação Matemática, pensando na escolarização de pessoas surdas, como os estudos de Oliveira (2005), Júnior e Ramos (2008), Souza (2010), Sales (2013) e Silva (2014). As discussões acerca das especificidades linguísticas destes estudantes tem sido tema recorrente destes estudantes e devem ser consideradas ao refletir sobre os processos de ensino e aprendizagem de Matemática para surdos.

Na pesquisa de Oliveira (2005), o origami teve papel fundamental no desenvolvimento de atividades sobre figuras planas e espaciais. Em um trabalho numa perspectiva inclusiva, a autora utilizou este recurso, considerado a importância da utilização de materiais concretos, por terem grande carga visual, sendo uma estratégia que auxiliou na interação entre estudante surdo e o professor ouvinte. Apesar da autora não apresentar especificidades do uso da comunicação em Libras durante as atividades realizadas, a opção por atividades com materiais concretos pode ser justificada pelo fato do estudante surdo possuir como natural a comunicação na modalidade visoespacial, como ressalta (MOURA, 2014). 
Júnior e Ramos (2008) investigam sobre a importância do ensino de matemática utilizando resolução de problemas na educação de surdos. Os autores discutem sobre a importância da utilização da Libras na aprendizagem destes estudantes e refletem sobre as dificuldades que os surdos podem encontrar para resolver problemas matemáticos decorrentes de enunciados formulados em Língua Portuguesa. Além disso, ao considerar as especificidades linguísticas do estudante surdo, o estudo apresenta a utilização de esquemas visuais como uma estratégia potencializadora da aprendizagem na resolução de problemas.

A utilização de recursos computacionais é apresentada na pesquisa de Souza (2010). A ferramenta MusiCALcolorida foi utilizada em investigações acerca da aprendizagem do conceito de número racional em atividades para estudantes surdos e ouvintes. A calculadora MusiCALcoloria faz uso de cores e notas musicais para favorecer a utilização por pessoas surdas e cegas. No trabalho realizado pelo pesquisador, um dos dificultadores foi a falta de alguns vocabulários específicos da matemática na Libras ao trabalhar alguns termos.

Na pesquisa de Sales (2013), a utilização de recursos visuais na educação de surdos foi o tema central. $O$ pesquisador buscou trabalhar com a visualização matemática e a geometria e, ressalta que é essencial que o professor busque estabelecer sua prática considerando as especificidades de cada estudante, no caso dos surdos, principalmente suas especificidades linguísticas, onde a ênfase na comunicação visual, proporcionou um desenvolvimento maior da criatividade e do pensamento.

Com o intuito de potencializar a utilização de teleaulas do Programa Telecurso 2000 por estudantes surdos, a pesquisa de Silva (2014) reelaborou o material para o ensino de frações buscando valorizar as potencialidades de cada um e a participação de todos. A autora compreende que tornar este material acessível para as pessoas surdas vai além de apenas disponibilizar a janela de Libras (garantida pelo Decreto 5296/2004), onde um intérprete realiza todas as falas na língua de sinais. Mudanças técnicas foram necessárias no material, bem como, uma nova análise e seleção dos exercícios propostos.

\section{DISCUSSÃO}

O reconhecimento da Libras como meio de comunicação oficial das comunidades surdas brasileiras modificou todo o cenário da educação de surdos e com o ensino da Matemática, não foi diferente e, o desenvolvimento de estudos em Educação Matemática que refletem sobre a educação de surdos tem se intensificado depois do decreto 5626/2005.

Com as políticas instituindo uma escola que deve atuar em uma perspectiva inclusiva, os pesquisadores que se preocupam com essa temática, têm buscado compreender como tornar as práticas de Matemática em propostas de ensino que valorizam as diferenças e oportunizem a participação de todos.

As particularidades linguísticas são ressaltadas em todas as pesquisas apresentadas sobre a educação de surdos e, decorrentes disso, os autores discutem metodologias que são mais adequadas para este público, como o uso de materiais concretos (OLIVEIRA, 2005; SALES, 2013), bem como a importância de desmistificar algumas verdades presentes em discursos estereotipados sobre surdez, como o fato de que apenas a presença de um intérprete de Libras em sala de aula já é suficiente para promover uma educação de qualidade para o estudante surdo.

O papel do intérprete é muito importante na escolarização destes estudantes, entretanto, nem todos os estudantes surdos ingressam na escola sabendo Libras. Moura (2014) aponta que um grande desafio na busca de uma escolarização de qualidade para os surdos, tem sido propiciar a aquisição da Libras com qualidade para crianças surdas, que geralmente são filhas de pais ouvintes e não tem contato com a Libras antes de ingressar na escola. 
É muito importante que a Libras esteja presente em seu universo da mesma forma que a língua oral está no universo das crianças ouvintes para que ela possa ser adquirida de forma completa, para que a criança surda possa dominá-la e se constituir como ser da linguagem. Dessa forma, a Libras, como uma primeira língua completamente adquirida, Ihe forneceria a base para poder aprender a sua segunda língua: a língua portuguesa (MOURA, 2014, p.27).

Deste modo, o AEE que deve ser ofertado para todos EPAEE no contraturno da escolarização, é um fator que colabora com a aprendizagem. No AEE, os estudantes surdos terão a oportunidade de estudar a Libras, os conteúdos vistos na classe regular em Libras e estudar a Língua Portuguesa na modalidade escrita, onde o professor especialista do AEE deve considerar suas especificidades como surdo e ter consciência de que a primeira língua destes estudantes é a língua de sinais.

Além disso, um fator que influência na aprendizagem destes estudantes é o fato do professor da sala regular não saber minimamente Libras. De acordo com Botelho (1998), isso não quer dizer que o professor deverá ministrar suas aulas fazendo uso simultâneo das duas línguas, Português e Libras, já que esta prática não seria viável, mas possibilitar momentos de interação direta com o estudante surdo pode enriquecer a aprendizagem.

(...) não é simplesmente a formação de professores proficientes em Libras que solucionará os problemas da educação de surdos. Isso envolve também o reconhecimento dos aspectos didáticos e metodológicos adaptados à cultura surda e à língua de sinais, que são diferentes de uma aula destinada a alunos ouvintes. Educação Inclusiva não significa apenas ofertar o acesso dos alunos às escolas ou à língua, é necessário a formação profissional específica para se trabalhar com esses alunos, e, também, saber lidar com as diferenças de cada aluno e interagir de forma correta com cada um deles (CAMPOS, 2014, p.53)

Considerar as diferenças de cada um é um processo muito importante para que a educação inclusiva seja efetivada. Cada pessoa possui suas particularidades e a valorização das potencialidades pode oportunizar um ensino que seja de qualidade, promova o desenvolvimento e não reforce estereótipos que ressaltam dificuldades e incapacidades.

\section{CONCLUSÃO}

A educação na perspectiva bilíngue é um direito para todos os estudantes surdos. Reconhecer o papel da Libras na escolarização deste público é o primeiro passo para uma educação que seja verdadeiramente inclusiva e que abrange estudantes que são usuários de uma língua que não é na modalidade oral. Além disso, temos que entender as questões linguísticas como necessárias, mas não suficientes. A adoção de práticas, como a utilização de recursos visuais e materiais concretos, ou a utilização de recursos metodológicos colaboram e são potencializadoras na promoção do ensino para todos, principalmente quando pensamos na educação de surdos. Entretanto, para que isso ocorra, são necessárias mudanças na formação inicial e, também, de novas ofertas de formação em serviço.

\section{REFERÊNCIAS}

BOTELHO, P. Segredos e silêncios na interpretação dos surdos. Belo Horizonte: Autêntica, 1998. 
BRASIL. Declaração de Salamanca e Linha de Ação sobre Necessidades Educativas Especiais. Brasília: Coordenadoria Nacional para Integração da Pessoa Portadora de Deficiência, 1994.

. Ministério da Educação. Secretaria de Educação Especial. Diretrizes Nacionais para a Educação Especial na Educação Básica. Brasília: MEC/SEESP, 2001.

. Lei no 10.436, de 24 de abril de 2002. Dispõe sobre a Língua Brasileira de Sinais - Libras e dá outras providências. Diário Oficial da União, Brasília, DF, 25 abr. 2002. Disponível em: http://www.planalto.gov.br/ccivil_03/leis/2002/l10436.htm. Acesso em: 01 mar. 2017.

. Decreto no 5296 de 2 de dezembro de 2004. Diário Oficial da União, Brasília, DF, 2 dez. 2004. Disponível em <www.planalto.gov.br/ccivil_03/_ato2004_2006/2004/decreto/d5296.htm>. Acesso em 13 jul.2017.

. Decreto no 5.626, de 22 de dezembro de 2005. Regulamenta a Lei no 10.436, de 24 de abril de 2002, que dispõe sobre a Língua Brasileira de Sinais - Libras, e o art. 18 da Lei no 10.098, de 19 de dezembro de 2000. Diário Oficial da União, Brasília, DF, 23 dez. 2005. Disponível em: <http://www.planalto.gov.br/ccivil_03/_ato20042006/2005/decreto/d5626.htm>. Acesso em: 01 mar. 2017.

- Ministério da Educação. Secretaria da Educação Especial. Política Nacional de Educação Especial, na perspectiva da Educação Inclusiva. Brasília: MEC/SEESP, 2008.

CAMPOS, M. L. I. L. Educação Inclusiva pra surdos e as políticas vigentes. In: LACERDA, C. B. F.; SANTOS, L. F. (Org.). Tenho um aluno surdo e agora? Introdução à Libras e educação de surdos. São Carlos: Edufscar, 2014. p. 37-61.

FERNANDES, S. Fundamentos para Educação Especial. Curitiba: Ibpex, 2007.

GOLDENBERG, M. A arte de pesquisar: Como fazer pesquisa qualitativa em Ciências Sociais. Rio de Janeiro / São Paulo: Record, 2004.

JUNIOR, H. A; RAMOS, M. G. Matemática para pessoas surdas: Proposições para o Ensino Médio. 2ㅇ Simpósio Internacional de Pesquisa em Educação Matemática. Recife. 2008.

MOURA, M. C. Surdez e Linguagem. In: LACERDA, C. B. F.; SANTOS, L. F. (Org.). Tenho um aluno surdo e agora? Introdução à Libras e educação de surdos. São Carlos: Edufscar, 2014. p. 13-26.

OLIVEIRA, J. S. A. Comunidade Surda: perfil, barreiras e caminhos promissores no processo de ensino-aprendizagem, 2005, 78f. Dissertação (Mestrado em Ensino de Ciências e Matemática) CEFET/RJ, 2005.

SALES, E. R. A visualização no ensino da Matemática: uma experiência com alunos surdos. 2013. 235 f. Tese (Doutorado em Educação Matemática), Instituto de Geociências e Ciências Exatas Unesp, Rio Claro/SP, 2013.

SILVA, E. L. Luz, câmera, ação: adaptando uma teleaula de frações para o público surdo. 2014. 111 f. Dissertação (Mestrado em Educação Matemática), Universidade Bandeirante Anhanguera, São Paulo/SP, 2014. 
SOUZA, F. R. Explorações de frações equivalentes por alunos surdos: uma investigação das contribuições da musiCALcolorida. 2010. 209 f. Dissertação (Mestrado em Educação Matemática), Universidade Bandeirante Anhanguera, São Paulo/SP, 2010. 